\title{
Rüzgar Türbin Kulesi Alternatiflerinin Çok Kriterli Karar Verme Yöntemleri İle Değerlendirilmesi
}

\author{
Muhammet Ensar Yiğit ${ }^{1}$, Muhammet Enes Akpınar ${ }^{2 *}$ \\ ${ }^{1}$ Manisa Celal Bayar Üniversitesi, Mühendilsik Fakültesi, İnşaat Mühendisliği Bölümü, Manisa, Türkiye, (ORCID: 0000-0003-0161-7144), ensar.yigit@ cbu.edu.tr \\ 2* Manisa Celal Bayar Üniversitesi, Mühendilsik Fakültesi, Endüstri Mühendisliği Bölümü, Manisa, Türkiye,(ORCID: 0000-0003-0328-6107),enes.akpinar@ cbu.edu.tr
}

(İlk Geliş Tarihi 4 Şubat 2021 ve Kabul Tarihi 4 Nisan 2021)

(DOI: $10.31590 /$ ejosat.874796)

ATIF/REFERENCE: Yiğit, M.E. \& Akpınar M.E. (2021). Rüzgar Türbin Kulesi Alternatiflerinin Çok Kriterli Karar Verme Yöntemleri İle Değerlendirilmesi. Avrupa Bilim ve Teknoloji Dergisi, (23), 386-393.

Öz

Yenilenebilir enerjinin öneminin daha fazla ön plana çıktığı 21. yüzyılda, en büyük doğal enerji kaynaklarından birisi de hiç kuşkusuz rüzgar enerjisidir. Rüzgar enerjisi için büyük boyutlarda rüzgar tribünlerine ihtiyaç vardır. Bazı durumlarda ise daha küçük ihtiyaçları gidermek için 10m boyutlarında tribün kuleleri kullanılabilmektedir. Bu kuleler çelik, hibrit, betonarme gibi çok farklı şekilde yapılardan oluşabilmektedir. Bu çalışma kapsamında üç farklı tip rüzgâr türbini kulelerinin Bulanık Analitik Hiyerarşi Süreci (BAHS) yöntemiyle seçimi üzerine bir probleme değinilmiştir. Kurulum ve bakım maliyetlerinin yanı sıra ekonomik ömrü sonundaki geri dönüşüm oranları gibi kriterler bu çalışmada dikkate alınmıştır. Bu kriterlere göre farklı en uygun rüzgar tribünü BAHS metodu ile analiz edilmiş ve en uygun kule tipinin seçimi yapılmıştır. Çalışma sonucunda gerek geri dönüşüm, bakım işletme ve montaj kolaylığı gerekse deplasman ve gerilme değerleri bakımından hibrit tipi kule ön plana çıkmıştır.

Anahtar Kelimeler: Rüzgar Türbin Kuleleri, Bulanık Analitik Hiyerarşi Süreci, Maliyet Analizi, Çok Kriterli Karar Verme.

\section{Evaulation of Wind Turbine Tower Alternatives With Multi Criteria Decision Making Method}

\begin{abstract}
One of the biggest natural energy sources in renewable energy is undoubtedly wind energy. Huge-sized wind turbine towers are used for wind energy. In some cases, tribune towers of 10 meters can be used to meet smaller needs. These towers can be composed of structures such as steel, hybrid and reinforced concrete. Within the scope of this study, three different types of wind turbine towers was selected using the Fuzzy Analytical Hierarchy Process (BAHS) method which is one of the multi-criteria decision making methods. In addition to the analysis of installation and maintenance costs, criteria such as recycling rates and economic life are taken into account in this study. According to these criteria, different most suitable wind turbine was analyzed with BAHS method and the most suitable tower type was selected. As a result of the study, the hybrid type tower came to the fore in terms of recycling, maintenance, operation and installation convenience, as well as displacement and stress values.
\end{abstract}

Keywords: Wind Turbine Columns, Fuzzy Analytical Hierarchy Process, Cost Analysis, Multi Criteria Decision Making.

\footnotetext{
*Sorumlu Yazar: enes.akpinar@cbu.edu.tr
} 


\section{Giriş}

Son birkaç yüzyılda dünya nüfusu katlanarak artmıştır. Nüfustaki bu hızlı artış nedeniyle enerji talebi de artmaktadır. Dünyadaki enerji talebini karşılamak için son yıllarda sürdürülebilir, yenilenebilir ve çevre dostu enerji kaynakları ile ilgili araştırmalara öncelik verilmektedir.

Rüzgar enerjisi, Nil nehri boyunca yelkenli geminin itici gücü olarak M.Ö. 5000'den beri kullanılmaktadır. Orta Çağ'da yel değirmenleri, tarımsal süreçlerin iyi bir entegre parçası olmuştur. 1887 'de elektrik üretimi için yapılan ilk yel değirmeni James Blyth tarafından İskoçya'da inşa edildi (Price, 2004). Bir tür temiz ve yenilenebilir enerji olan rüzgar enerjisi, yeşil enerjinin önemli bir parçası haline gelmiştir. 20. yüzyılda kömürden üretilen elektrik rüzgârdan daha ucuz olması nedeniyle 20. yüzyılın sonlarında yakıt fiyatları önemli ölçüde yükselene kadar rüzgar enerjisi sisteminin araştırmaları yoğunlaşmamıştır. Günümüzde rüzgar türbinleri diğer enerji kaynakları ile rekabet edebilmekte ve bu da tek bir rüzgar türbini tarafından üretilen gücün ve elektrik üretiminin verimliliğinin artırılması konusunda birçok araştırmaya yol açmıştır (Abbate, 2013).

2019 yılında, Avrupa Birliği genelinde mevcut rüzgar enerjisi kapasitesi $205 \mathrm{GW}$ olarak tahmin edilmekte ve kurulu rüzgar enerjisi santrali $15.2 \mathrm{GW}$ gücündedir. Bunların 11.6 GW'1 karada ve 3.36 GW'1 açık denizdedir. Rüzgar enerjisi şuan Avrupa Birliği'nin elektrik talebinin \%15'ini karşılamaktadır. 2018 yılı ile karşılaştırıldığında 2019 yılında AB'de kurulu rüzgar santralleri sayısında \% 27 artış olmuştur (WindEurpe, 2020). Temiz ve yenilenebilir bir enerji kaynağ1 olan rüzgar enerjisinin güç çıkışını daha da artırmak için, daha yüksek rakımlarda yoğun hızlardan yararlanabilen daha yüksek uygulamalara olan talep ortaya çıkmıştır. Bunu başarmak için, destek yapısı için kafes ve boru şeklindeki parçaları birleştiren hibrit çelik rüzgar kuleleri umut verici bir çözüm olabilmektedir. Gkantou vd. çalışmasında yüksek bir hibrit rüzgar türbini kulesinin yapısal tepkisi incelenmiş ve elde edilen sonuçlar tartışılmıştır (Gkantou, Baniotopoulos ve Martinez, 2017).

Richter, Mohammadi, Pak, Rebelo ve Feldmann, (2017) makalesinde, alt kısım kafes ve üst kısım boru şeklindeki hibrit rüzgar türbinlerinin kurulmasında kullanılan en son teknolojilerden bahsetmiştir. Çalışmada kurulma işlemi, yüklerin hesaplanması ve kaldırma işleminin tasarlanması için farklı adımlar ve geçiş parçası sunulmuştur. Quilligan, O'Connor ve Pakrashi (2012) farklı kule yükseklikleri ve rüzgar hızları için kanat şeklinde sayısal bir model kullanarak çelik ve beton kulenin performansını araştırmıştır. Çalışmada öngerilmeli beton kulelerin uygun bir alternatif sağlayabileceğini ve gelişmiş bir performans sunabileceğini öne sürülmüştür. Elibüyük ve Üçgül (2014) çalışmasında rüzgâr türbinleri dönme eksenlerine, devirlerine, güçlerine, kanat sayılarına, rüzgâr etkisine, dişli özelliklerine ve kurulum konumlarına göre sınıflandırılmasından bahsetmiştir. Ayrıca çalışmasında rüzgâr enerjisinin farklı depolama yöntemleri ve yeni gelişmeler hakkında bilgi vermiştir.

Soğukpınar ve diğ. (2015) yerel tesislerin kullanımı için 2 kW'lık mikro türbinler tasarlamış, üretmiş ve test etmiştir. Çalışmalarında düşük rüzgar hızlarında kullanılmak üzere bir mikro türbin tasarlamak, mikro türbin üretimi ile ilgili endüstriyel altyapı oluşturmak ve yerel endüstri için farklı üretim teknolojilerinin geliştirilmesi amaçlanmıştır. Yavuz ve Özbay (2020) çalışmalarında, rüzgar türbinlerinin temel bileşenleri, nakliye süreci, ekipman kurulumları ve servis süreçlerini incelemiştir. İşletme ve bakım konusunda dikkat edilmesi gereken hususlar konusunda bilgiler vermişlerdir.. Ayrıca rüzgar potansiyeli açısından bölgesel incelemeler yapıp kurulu rüzgar enerji santralleri hakkında detaylı bilgiler vermişlerdir.

Rüzgar enerjisinden elektrik üretimi ağırlıklı olarak kara ve deniz rüzgar çiftlikleri tarafından sağlansa da, bu teknolojiler hakkında birçok bilinmeyen vardır. Sı̆̆ suda deniz yatağına sabitlenmiş tekil kazık destek yapısına sahip açık deniz rüzgar türbinleri halihazırda sanayileşmiştir, daha derin sularda sabit türbinler ortaya çıkmakta ve yüzer rüzgar türbinleri hala gelişimin erken bir aşamasındadır (Moan, 2017).

Laxson (2001) çalışmasında $750 \mathrm{~kW}-5000 \mathrm{~kW}$ arasında değişen 5 farklı güçte rüzgar türbinin üç farklı yöntemle kurulum ve işletme maliyetlerini raporlaştırmış ve bu türbinlerin değişik yüksekliler için maliyet / metre $(\$ / \mathrm{m})$ değerini veren denklemler elde etmiştir.

Son yıllarda, çeşitli kule yapılarının tasarımını optimizasyon problemleri olarak formüle etmek için önemli miktarda araştırma yapılmıştır. Kule montaj maliyetinin minimizasyonu, kule rijitliğinin maksimizasyonu, titreşimlerin minimizasyonu ve geri dönüşüm oranının maksimizasyonu doğrultusunda optimizasyon stratejileri çalışılmıştır (Negm ve Maalawi, 1999; Şermet, Yiğit ve Hökelekli, 2019). Modal parametrelere ek olarak, montaj maliyeti ve geri dönüşüm oranı da optimizasyon parametreleri olarak kabul edilir. Özellikle kulenin yüksekliği önemli bir parametredir (Kocer ve Arora, 1999).

Çok kriterli karar verme yötemleri birçok çalışmada kullanılmaktadır (Akpınar, 2016). Bu çalışmada kullanılan bulanık AHP yöntemi daha literatürde tedarikçi seçiminde Krishnendu, Ravi, Surendra, ve Lakshman, (2012), bulanık TOPSİS ile entegre edilerek dağıtım kanallarının yönetiminde Paksoy,Pehlivan ve Kahraman, (2012), web sitelerin değerlendirilmesinde Lin (2010), bilgisayar destekli sistemlerinin seçiminde Orlando (2011), Ar-Ge performans ölçümünde Lee ve diğ. (2010), sağlık alanında Uzoka ve diğg. (2011), banka kredisi kararında Che, Wang ve Chuang, (2010), makine seçiminde Taha ve Rostam, (2011), güzergah alternatiflerinin değerlendirilmesinde Arslan ve Khirsty (2006), rüzgar enerji tesis yatırımın değerlendirilmesinde (Artun, 2020), risk değerlendirmesinde (Lyu, Sun, Shen ve Zhou, 2020) ve daha birçok farklı karar problemlerine uygulanmıştır (Liu, Eckert, ve Earl, 2020).

Literatür araştırmasında görüldüğü üzere bulanık AHP yöntemi daha önce rüzgar tribünü seçiminde kullanılmamıştır. Literatürdeki bu boşluğu doldurmak için bu çalışmada bulanık AHP yöntemini kullanarak en uygun rüzgar tribünü seçimine karar verilmiştir. Çalışmanın geri kalanı şu şekilde oluşturulmuştur: Bulanık AHP yöntemi Bölüm 2'de detaylı bir şekilde anlatılmıştır. Bölüm 3'te rüzgar tribünü kulesi seçim probleminden bahsedilmiş ve uygulaması yapılmıştır. Geometrik olarak aynı boyutta olan üç farklı kule tipinin montaj maliyetleri, yıllık bakım ve işletme maliyeti, geri dönüşüm oranları, yer değiştirmeler ve gerilme değerleri açısından karşılaştırılmıştır. Son bölümde ise BAHP sonuçları yorumlanmış ve gelecek çalışmalar hakkında bilgi verilmiştir. 


\section{Bulanık AHP Yöntemi}

Bulanık AHP yönteminin geçmişi 1996 yılında Chang, (1996) tarafindan yazılan "Application of the Extent Analysis Method on Fuzzy AHP" isimli makalede ilk olarak ortaya çıkmıştır. AHP ile birlikte üçgensel bulanık sayıları karşılaştırmak için geliştirilen bir metottur. Çok kullanışlı ve kolay uygulanabilir bir yöntemdir.

$X=\{x 1, x 2, \ldots, x n\}$ bir nesneler kümesi ve $U=\{u 1, u 2, \ldots$, un\} de bir amaçlar kümesi olsun. Genişletilmiş analiz değeri Denklem (1)'deki gibi elde edilir.

$M_{g i}^{1}, M_{g i}^{2}, \ldots, M_{g i}^{m} \quad i=1,2, \ldots, n$

Buradaki tüm $\mathrm{M}_{\mathrm{gi}}^{\mathrm{j}} \mathrm{j}=(1,2, \ldots, \mathrm{m})$ değerleri üçgen bulanık sayıları ifade etmektedir. Chang tarafindan önerilen genişletilmiş analizin adımları aşağıdaki gibidir (Chang, 1996):

Adım 1: $i$. nesne için bulanık değer Denklem (2)'deki gibi ifade edilir:

$S_{i}=\sum_{j=1}^{m} M_{g i}^{j} \otimes\left[\sum_{i=1}^{n} \sum_{j=1}^{m} M_{g i}^{j}\right]^{-1}$

Burada $S_{i}, i$. amacın sentez değerini $\mathrm{M}_{\mathrm{gi}}^{\mathrm{j}}$ her bir amaca yönelik genişletilmiş değeri ifade etmektedir.

$\sum_{j=1}^{m} M_{g i}^{j}$ değeri için $m$ adet genişletilmiş analiz değeri bir matris elde edilir. Bu matris Denklem (3) ile elde edilir.

$\sum_{j=1}^{m} M_{g i}^{j}=\left(\sum_{j=1}^{m} l_{j}, \sum_{j=1}^{m} m_{j}, \sum_{j=1}^{m} u_{j}\right)$

$\left[\sum_{\mathrm{j}=1}^{\mathrm{n}} \sum_{\mathrm{j}=1}^{\mathrm{m}} \mathrm{M}_{\mathrm{gi}}^{\mathrm{j}}\right]^{-1}$ formülasyonunu hesaplayabilmek için $\mathrm{M}_{\mathrm{gi}}^{\mathrm{j}}(\mathrm{j}=$ $1,2, \ldots, \mathrm{m}$ ) bulanık toplama işlemi Denklem (4)'te gösterildiği şekliyle uygulanır.

$\left[\sum_{j=1}^{n} \sum_{j=1}^{m} M_{g i}^{j}\right]^{-1}=\left[\frac{1}{\sum_{i=1}^{n} u_{i}}, \frac{1}{\sum_{i=1}^{n} m_{i}}, \frac{1}{\sum_{i=1}^{n} l_{i}}\right]$

Adım 2: Ağırlık değerleri elde edilir ve bulanık sayıların karşılaştırılması aşağıdaki şekilde yapılır:

$\widetilde{M}_{1}=\left(l_{1}, m_{1}, u_{1}\right)$ ve $\widetilde{M}_{2}=\left(l_{2}, m_{2}, u_{2}\right)$ iki üçgen bulanık sayıyı gösterir. $\widetilde{M}_{2} \geq \widetilde{M}_{1}$ eşitliğinin olabilirlik derecesi şu şekilde tanımlanabilir:

$V\left(\widetilde{M}_{2} \geq \widetilde{M}_{1}\right)=\sup _{y \geq x}\left[\min \left(\mu_{\widetilde{M}_{1}}(x), \mu_{\widetilde{M}_{2}}(y)\right\rfloor\right.$
$\widetilde{M}_{1}=\left(l_{1}, m_{1}, u_{1}\right)$ ve $\widetilde{M}_{2}=\left(l_{2}, m_{2}, u_{2}\right)$ bulanık say1lar iken (Chang, 1996):

$\left(\widetilde{M}_{2} \geq \widetilde{M}_{1}\right)=$ yükseklik $\left(\widetilde{M}_{1} \cap \widetilde{M}_{2}\right)=\mu_{\widetilde{M}_{2}}(d)$

$$
=\left\{\begin{array}{cc}
1 & \text { e⿳̆er } m_{2} \geq m_{1} \\
0 & \text { eğer } l_{1} \geq u_{2} \\
\frac{l_{1}-u_{2}}{\left(m_{2}-u_{2}\right)-\left(m_{1}-l_{1}\right)}, & \text { diğer durumlarda }
\end{array}\right.
$$

Adım 3: Konveks bir bulanık sayının $k$ adet bulanık sayıdan, $M_{i}(i=1,2, \ldots, k)$ daha büyük olabilirlik derecesi şu şekilde tanımlanır:

$$
\begin{array}{r}
V\left(M \geq M_{1}, M_{2}, \ldots, M_{k}\right) \\
=V\left[\left(M \geq M_{1}\right),\left(M \geq M_{2}\right), \ldots,(M\right. \\
\left.\left.\geq M_{k}\right)\right] \\
\quad=\operatorname{minV}\left(M \geq M_{i}\right), i \\
=1,2,3, \ldots, k
\end{array}
$$

$\mathrm{Bu}$ durumda $\mathrm{S}_{\mathrm{j}}$ 'ler için şu varsayımlar yapılmıştır $k=$ $1,2, \ldots, n ; k \neq j$ için $d\left(A_{i}\right)=\min V\left(S_{i} \geq S_{k}\right)$.

Daha sonar ağırlık vektörü $A_{i}(\mathrm{i}=1,2, \ldots, \mathrm{n})$ 'nin $\mathrm{n}$ elemanda oluştuğu şu şekilde ifade edilir:

$W^{\prime}=\left(d^{\prime}\left(A_{1}\right), d^{\prime}\left(A_{2}\right), \ldots, d^{\prime}\left(A_{n}\right)\right)^{T}$

Adım 4: Normalizasyon ile normalize edilmiş ağırlık vektörü $\mathrm{W}$ elde edilir ve burada $\mathrm{W}$ bulanık bir sayı değildir.

$W=\left(d\left(A_{1}\right), d\left(A_{2}\right), \ldots, d\left(A_{n}\right)\right)^{T}$

Hesaplamaların sonunda bulanık sayıların sıralanması için ltieratürde Chang, Liou ve Wang, Abdel-Kader ve Dugdale, Kareli ortalamalar ve Kwong-Bail yöntemleri kullanılmaktadır. $\mathrm{Bu}$ çalışmada kareli ortalamalar ve Kwong-Bai yöntemi kullanılmıştır. Bu yöntemleri kısaca bakacak olursak:

Kareli ortalama sıfir ya da negatif sayıların bulunduğu durumlarda kullanılmaktadır. Burada bulanık sayının sinırlarından biri sifir ya da negatif olma durumunda siralamaya imkan verebilmektedir. Bu yöntemde $\tilde{A} k=(l, m, u)$ üçgen bulanık sayı Denklem (11)'deki gibi hesaplanır ve sıralanır.

$K\left(A_{k}\right)=\sqrt{\frac{l^{2}+m^{2}+u^{2}}{3}}$

Kwong-Bail yönteminde ise üçgen bulanık sayıları sıralamak için aşağıdaki denklemi kullanmışlardır. $\tilde{A} k=(l, m, u)$ 
üçgen bulanık sayı olmak üzere Denklem (12)'deki şeklinde siralama yapar.

$M_{k}=\frac{l+4 m+u}{6}$

Tutarlılık indeksi hesaplanırken, $\lambda_{\text {max }}$ matematiksel olarak tanımsız çıkabilmektedir. $\mathrm{Bu}$ sebeple bu çalışmada, sentez değerleri Chang yöntemine göre elde edilmiş ve sonrasında nihai sıralama için Kwong-Bai ve Kareli Ortalama yöntemleri karşılaştırma için kullanılmıştır. Ayrıca, klasik AHP'de kullanılan farklı ölçek türlerinden Tablo 1'de gösterilen ölçek bu çalışmada kullanılmıştır.

Tablo 1: Bulanık ölçekler

\begin{tabular}{|l|c|c|}
\hline Önem düzeyi & Bulanık Ölçek & Karşılık Ölçek \\
\hline Eşit önemli & $(1,1,1)$ & $(1,1,1)$ \\
\hline Biraz daha önemli & $(1 / 2,5 / 4,2)$ & $(1 / 2,4 / 5,2)$ \\
\hline Kesinlikle önemli & $(3 / 2,9 / 4,3)$ & $(1 / 3,4 / 9,2 / 3)$ \\
\hline $\begin{array}{l}\text { Çok kesinlikle } \\
\text { onemli }\end{array}$ & $(5 / 2,13 / 4,4)$ & $(1 / 4,4 / 13,2 / 5)$ \\
\hline Tamamen önemli & $(7 / 2,17 / 4,5)$ & $(1 / 5,4 / 17,2 / 7)$ \\
\hline
\end{tabular}

\section{Bulanık AHP Yönteminin Rüzgar Türbini Kulesi Seçimine Uygulanması}

$\mathrm{Bu}$ bölümde bulanık AHP yönteminin uygulamasından bahsedilmiştir. Öncelikle rüzgar türbin kulelerinin tanımları ayrıntılı olarak yapılmıştır. Sonrasında bu tribünlerin tasarımı hakkında bilgi verilmiștir. Son bölümde ise bulanık AHP ile en uygun rüzgar tribün kulesinin seçim problemine değinilmiştir.

\subsection{Rüzgar türbin kulesi tanımı}

Rüzgar türbini kuleleri pervane ve jeneratör-dişli odasını rüzgar hızlarının etkili olduğu yüksekliklerde tutan yapılardır. Kuleler farklı malzemeler ve farklı yapı sistemleriyle inşa edilebilmektedir. Örneğin çelik kafes kuleler, çelik silindirik kuleler, betonarme kuleler ve hibrit kuleler (Şekil 1). Kısa türbin kulelerinin en kesitleri kule boyunca sabit iken uzun kulelerin en kesiti tepeden tabana doğru tedrici artan şekilde imal edilir. Rüzgar türbini sistemlerinde üretim kapasitesini artırmak için etkili rüzgar hızlarının elde edileceği daha yüksek kulelerin inşa çalışmaları devam etmektedir (Şermet ve diğ., 2019).

Silindirik çelik kuleler: Günümüzde en çok tercih edilen kule tipi çelik silindirlerdir. Bu şekilde kule yapısı hafif ve yüksek mukavemet özellikleri gösterir (Manwel ve diğ., 2009). Diğer kule tiplerine göre daha güvenli bir tırmanma alanı ve daha düşük montaj maliyetleri ve yüksek geri dönüşüm oranı sağladığı için de tercih edilmektedir (Şekil 1.a). Çelik kulelerin korozyona karşı bakım maliyetleri diğer kulelere göre da fazla olmaktadır. Türbin kulesi hem içten hem de dıştan gerekli bakımları ihmal edilmemelidir.

Hibrit kuleler: Hibrit kulelerde çelik ve betonarme yap1 sistemleri birlikte kullanılmaktadır (Şekil 1.b). Rüzgar türbini kulelerinin hafif ve son derece dayanıklı olması gerekir. Bazı yüksek kule tasarımlarında betonarme sistem estetik açıdan dengesiz yapıların oluşmasına, çok ağır ve bakımı zor hale gelmesinden dolayı avantajlı olmaktan çıkmaktadır. Hibrit kuleler de iki inşaat sisteminin avantajlarından yararlanmaktadır. $\mathrm{Bu}$ avantajlarının yanı sıra kule üzerindeki deprem yüklerini de azalmaktadır (Şermet vd. 2019).

Betonarme kuleler: Betonarme sistemler dünya inşaat sektöründe en yaygın kullanılan yöntemlerdir. $\mathrm{Bu}$ sistemler hemen hemen her ülkede yaygın olarak kullanılmaktadır. Aynı şekilde rüzgar türbini kulesi inşaatlarında da bu sistem kullanılmaktadır. Kule yükseklikleri artan diğer türbin kulelerindeki rezonans eğilimi, betonarme kulelerin tasarımına yol açar (Harte, Gideon ve Zijl, 2007; Lewin, 2010). Bu tür kulelerin en büyük avantajı, yerel burkulmanın önlenmesidir. Betonarme kulelerin dezavantajları, diğer kule tiplerine göre montaj maliyetinin daha yüksek olması, aynı zamanda geri dönüşüm oranının daha düşük olmasıdır (Şekil 1.c).

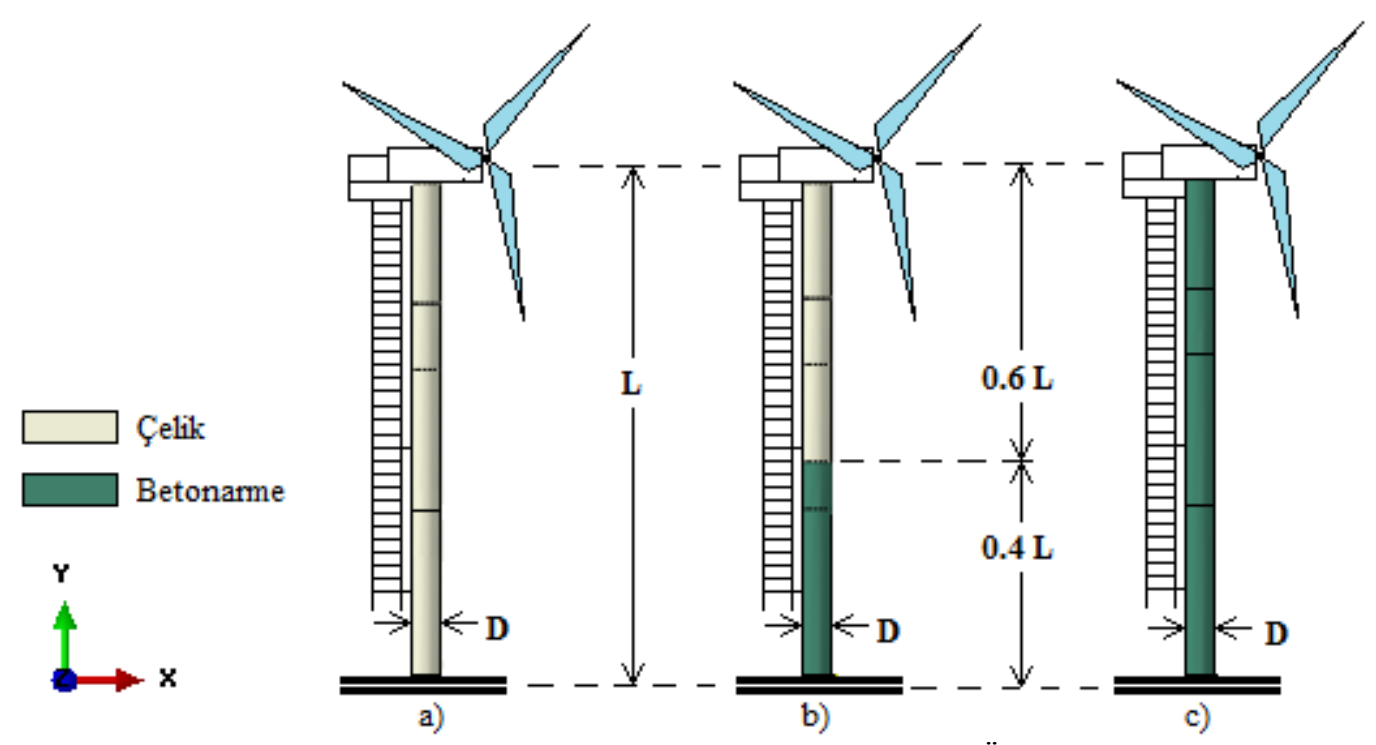

Şekil 1. a) Çelik, b) Hibrit ve (c) Betonarme Türbin Kulesi Kesit ve Ölçüleri (Şermet vd. 2019). 


\subsection{Endüstriyel rüzgar tribünlerinin tasarımı ve maliyet analizi}

Endüstriyel rüzgar türbinlerini seçmenin nedeni, daha küçük enerji santrallerine olan büyük talepten kaynaklanmaktadır. Çünkü daha küçük santraller, küçük kasaba veya kuruluşların kullanılması için gerekli olan enerjiyi sağlamak için yeterlidir. Bu tip üretimin en büyük avantajı tüketim anında gerçekleşmesi, depolama yapılmaması, iletim ve enerji kayıplarının neredeyse sıfira indirilmesidir.

Bu bölümde; her biri $15 \mathrm{~kW}$ gücündeki çap1; $\mathrm{D}=0.45 \mathrm{~m}$ ve yüksekliği; $\mathrm{L}=10 \mathrm{~m}$ silindirik formda betonarme, çelik ve hibrit (betonarme ve çelik) rüzgar türbini kuleleri kullanılmıştır. Silindirik çelik kulenin et kalınlığ 5 mm'dir. Çelik tipi S-335'tir. Beton karışımının basınç dayanımı ve yoğunluğu sırasıyla 35 MPa ve $2400 \mathrm{~kg} / \mathrm{m}^{3}$ olup, betonun poisson oran $10,3^{\prime}$ tür. Betonarme kule tasarımında $16 \phi 16$ donatı kullanılmıştır. $\mathrm{Bu}$ tasarımlar imalat maliyetlerinin birbirine çok yakın olmasından dolayı seçilmiştir (Şermet ve diğ., 2019; Yiğit ve diğ., 2018).

Türbin kurulumunda; kurulumun yapılacağı konum, kullanılacak ekipmanlar, türbin sayısı, ve kurulum işçiliği maliyeti etkileyen başlıca etmenlerdir. Kule yapısı vemontaj maliyetleri türbin gücüne ve kullanılan vinç modeline göre değişiklik göstermektedir (Şekil 2-3) (Laxson, 2001). Ayrıca ön üretim türbin kulelerinin taşınması, yerinde yapılacak türbin kulesi ve temel hazırlığı maliyetleri de önemli etmenlerdir. Her üç tip kule için ortak olan temel yapısı, ulaşım, jeneratör, dişli, kanat vb. diğer maliyet ve etkiler hesaplamalarda ayırt edici etken olmadığı için ihmal edilmiş̧ir. Şekil 2-4' den yararlanarak çelik, hibrit ve betonarme türbin kulesi için yaklaşık maliyetler hesaplanmış ve Tablo 2'de verilmiştir. Yıllık bakım-işletme maliyeti için görsel kontrol, yağlama, elektrik kontrol, makine bakımı, kule boyama, tamirat, malzeme, iskele temini ve işçiliği yaklaşık olarak alınmıştır. Ekonomik ömür sonrası geri dönüşüm değerleri ise imalatta kullanılan ve yıkım sonrasında ortaya çıkacak olan çelik miktarına göre hesaplanarak Tablo 2.'de verilmiştir.

\subsection{Problemin tanımlanması}

Bu bölümde rüzgar türbin kulesi seçim problemi detaylı bir şekilde anlatılmıştır. Rüzgar türbin kulesi seçimi ile ilgili alternatifler önceki bölümde detaylı bir şekilde bahsedilmişti. Bu aşamada seçim kriterleri ve problemin çözümüne ilişkin aşamalar verilmiştir. En uygun rüzgar türbin kulesi seçim kriterleri literatürdeki kriterler dikkate alınarak aşağıdaki şekilde oluşturulmuştur.

Yer değiştirme $\left(C_{l}\right)$ : Türbin kulesinin tepe noktasındaki yatay yer değiştirmeyi ifade etmektedir. Yer değiştirme değerinin belirli salınım sınırları içerisinde kalması büyük önem arz eder. Aksi halde yapıda şekil bozukluğuna ve yapının göçmesine neden olur. Ayrıca salınımlar jeneratör-diş̧li odasındaki makinelerin çalışma düzenini bozabilir.

Gerilme $\left(C_{2}\right)$ : Türbin kulesini oluşturan yap1 malzemeleri üzerinde birim alana düşen çekme ve basınç kuvvetlerini ifade etmektedir. Gerilme değeri kullanılan yapı malzemesinin emniyet gerilmesi değerlerinin üzerine çıktığı durumlarda yapının göçmesine neden olur.

Montaj maliyeti $\left(C_{3}\right)$ : Türbin kurulumu için gerekli malzemelerin birleştirilerek yapının kurulması aşamasında önemli bir etmendir. Ön üretimli, hafif ve pratik bağlantılara sahip yapı bileşenlerinin montajında düşük değerler alırken, hibrit sistemlerde ve yerinde imalat gerektiren, ağır yapı elemanları nedeniyle ağır iş vinçleri gerektiren montaj işlemlerinde daha yüksek değerler almaktadır.

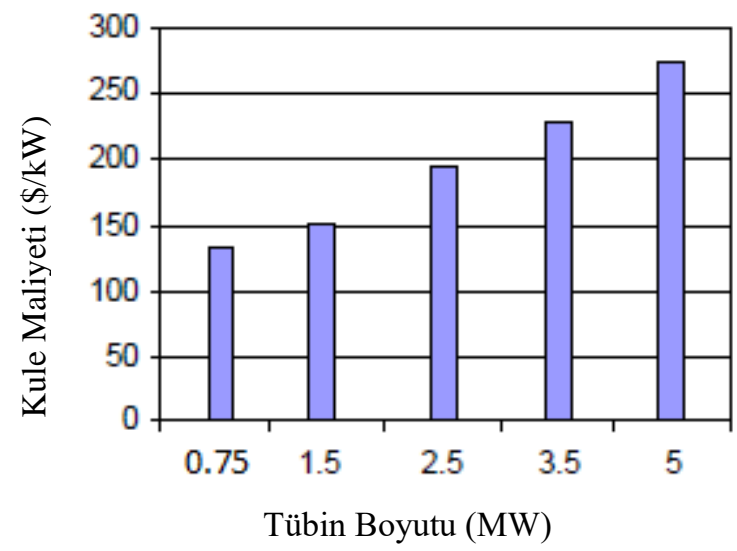

Şekil 2. Türbin Boyutunun Bir Fonksiyonu Olarak Kule Maliyetleri (Laxson 2001).

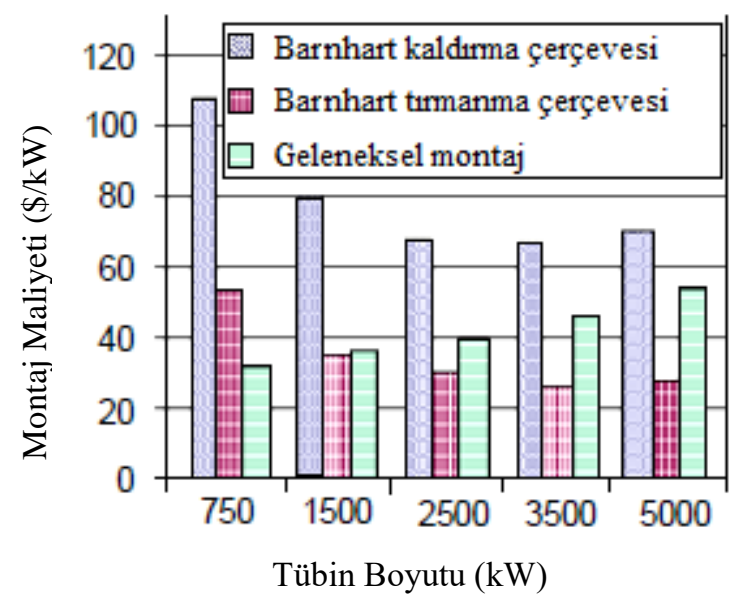

Şekil 3. Türbin Kulesi Kaldırma Maliyetleri (Laxson 2001).

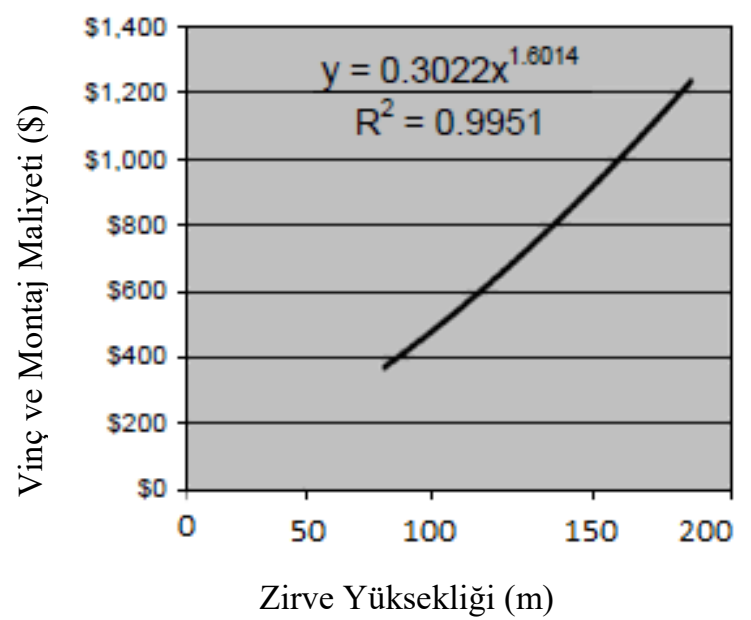

Şekil 4. Zirve Yüksekliğine Göre En Uygun Vinç ve Montaj Maliyeti (Laxson 2001). 
Ylllık baklm ve işletme giderleri $\left(C_{4}\right)$ : Türbin kulesinin ekonomik ömrü boyunca maruz kalacağı yıpratıcı dış etmenlerin verdiği hasarların iyileştirilmesi ve sağlıklı çalışmasına devam etmesi için gereken periyodik bakımların maliyetini ifade etmektedir. Türbin kulelerinin yüksekliğine ve sayısına göre değişen önemli bir etmendir.

Geri dönüşüm yüzdesi $\left(C_{5}\right)$ : Türbin kulesinin ekonomik ömrünün sonunda geri dönüşümle tekrar kullanılabilecek yapı bileşenlerinin maliyetinin tüm yapı bileşenlerinin maliyetine oranını ifade eder. Çelik kuleler geri dönüşüm oranı yüksek değerde olduğu için avantajlı konumdadır. Doğanın korunması için imalat aşamasındaki karbon izinin küçük, geri dönüşüm oranının büyük değerlerde olması daha çok önem arz eder.

Her bir kriter için rüzgar türbin kulesi alternatiflerinin değerlendirilmesi Tablo 2'de verilmiştir. Çelik türbin kulesi en düşük montaj maliyetine sahip iken betonarme kule en yüksek maliyetli türbin kulesi olarak görülmektedir. Yer değiştirme oranı en yüksek olan çelik rüzgar tribünüdür. Bu şekilde hangi kriterde hangi alternatifin daha güçlü olduğu Tablo 3'de görülmektedir. Çalışmada amaç tüm kriterleri en uygun düzeyde karşılayan alternatif yani rüzgar türbin kulesine karar vermektir. Kriter ve alternatifler belirlendikten sonra Tablo 1 dikkate alınarak üçgen ikili karşılaştırma matrisi oluşturulur. Bu matris Tablo 3 'te verilmiştir.

Tablo 2. Farklı Tip Türbin Kulelerinin Karşılaştırma Değerleri (Laxson, 2001; Yiğit vd. 2018).

\begin{tabular}{|l|c|c|c|}
\hline & $\begin{array}{c}\text { Çelik } \\
\left(\mathbf{A}_{1}\right)\end{array}$ & $\begin{array}{c}\text { Hibrit } \\
\left(\mathbf{A}_{2}\right)\end{array}$ & $\begin{array}{c}\text { Betonarme } \\
\left(\mathbf{A}_{\mathbf{3}}\right)\end{array}$ \\
\hline Yer değiştirme (m) & 0.12 & 0.067 & 0.058 \\
\hline Gerilme (MPa) & 168.203 & 94.711 & 72.029 \\
\hline Montaj Maliyeti (\$) & 110.42 & 327.12 & 465.43 \\
\hline $\begin{array}{l}\text { Y1llık bakım ve } \\
\text { işletme gideri(\$) }\end{array}$ & 355.23 & 262.80 & 132.56 \\
\hline $\begin{array}{l}\text { Geri Dönüşüm } \\
\text { Yüzdesi (\%) }\end{array}$ & 95 & 74 & 45 \\
\hline
\end{tabular}

Tablo 3. Kriterler Arasında Karşılıklı Değerlendirme Matrisi

\begin{tabular}{|l|c|c|c|c|c|}
\hline & C1 & C2 & C3 & C4 & C5 \\
\hline C1 & $(1,1,1)$ & $(1 / 2,5 / 4,2)$ & $(1 / 2,5 / 4,2)$ & $(7 / 2,17 / 4,5)$ & $(3 / 2,9 / 4,3)$ \\
\hline C2 & $(1 / 2,4 / 5,2)$ & $(1,1,1)$ & $(1,1,1)$ & $(3 / 2,9 / 4,3)$ & $(1 / 2,5 / 4,2)$ \\
\hline C3 & $(1 / 2,4 / 5,2)$ & $(1,1,1)$ & $(1,1,1)$ & $(5 / 2,13 / 4,4)$ & $(3 / 2,9 / 4,3)$ \\
\hline C4 & $(1 / 5,4 / 17,2 / 7)$ & $(1 / 3,4 / 9,2 / 3)$ & $(1 / 2,4 / 5,2)$ & $(1,1,1)$ & $(1 / 2,4 / 5,2)$ \\
\hline C5 & $(1 / 3,4 / 9,2 / 3)$ & $(1 / 2,4 / 5,2)$ & $(1 / 3,4 / 9,2 / 3)$ & $(1 / 2,5 / 4,2)$ & $(1,1,1)$ \\
\hline
\end{tabular}

Adım 1. Denklem (2-4) kullanılarak her bir kriter için bulanık değerler hesaplanır.

$S_{C 1}=(7,10,13) \otimes(1 / 45.26,1 / 31.8,1 / 23.19)$

$=(0.15,0.31,0.56)$

e-ISSN: 2148-2683
$S_{C 2}=(5.5,6.3,9) \otimes(1 / 45.26,1 / 31.8,1 / 23.19)$

$=(0.12,0.2,0.39)$

$S_{C 3}=(6.5,8.3,11) \otimes(1 / 45.26,1 / 31.8,1 / 23.19)$

$=(0.14,0.26,0.47)$

$S_{C 4}=(2.53,3.27,5.94) \otimes(1 / 45.26,1 / 31.8,1 / 23.19)$

$=(0.06,0.1,0.26)$

$S_{C 5}=(2.66,3.93,6.32) \otimes(1 / 45.26,1 / 31.8,1 / 23.19)$

$=(0.06,0.12,0.27)$

Adım 2. Her bir kriter için Denklem (5-7) kullanılarak $V\left(\widetilde{M}_{2} \geq \widetilde{M}_{1}\right)$ değeri hesaplanır.

$V\left(S_{C 1} \geq S_{C 2}\right)=1, V\left(S_{C 1} \geq S_{C 3}\right)=1$,

$V\left(S_{C 1} \geq S_{C 4}\right)=1, V\left(S_{C 1} \geq S_{C 5}\right)=1$

$V\left(S_{C 2} \geq S_{C 1}\right)=0.68, V\left(S_{C 2} \geq S_{C 3}\right)=0.8$,

$V\left(S_{C 2} \geq S_{C 4}\right)=1, V\left(S_{C 2} \geq S_{C 5}\right)=1$

$V\left(S_{C 3} \geq S_{C 1}\right)=0.86, V\left(S_{C 3} \geq S_{C 2}\right)=1$,

$V\left(S_{C 3} \geq S_{C 4}\right)=1, V\left(S_{C 3} \geq S_{C 5}\right)=1$

$V\left(S_{C 4} \geq S_{C 1}\right)=0.34, V\left(S_{C 4} \geq S_{C 2}\right)=0.58$,

$V\left(S_{C 4} \geq S_{C 3}\right)=0.43, V\left(S_{C 4} \geq S_{C 5}\right)=0.91$

$V\left(S_{C 5} \geq S_{C 1}\right)=0.39, V\left(S_{C 5} \geq S_{C 2}\right)=0.65$,

$V\left(S_{C 5} \geq S_{C 3}\right)=0.48, V\left(S_{C 5} \geq S_{C 4}\right)=1$

Adım 3. Denklem (8) ve Denklem (9) kullanılarak ağırlık vektörüne karar verilir.

$W^{\prime}=(1,0.68,0.86,0.34,0.39)$

Adım 4. Ağırlık vektörü normalize edilir.

$W=(0.31,0.21,0.26,0.1,0.12)^{T}$

Sonrasında her bir alternatif için her bir kritere göre ikili karşılaştırma matrisleri oluşturulmuştur. Bu matrisleri "Super Decision" paket programı kullanarak çözülmüş ve sonuçlar Tablo 4 ve Tablo 5'de verilmiştir.

Tablo 4: Kareli Ortalamalar Yöntemine Göre Alternatiflerin Değerlendirilmesi

\begin{tabular}{|c|c|c|c|c|}
\hline Alternatifler & Toplam & Normal & İdeal & Siralama \\
\hline $\mathbf{A}_{\mathbf{1}}$ & 0.0883 & 0.3189 & 0.6441 & 2 \\
\hline $\mathbf{A}_{\mathbf{2}}$ & 0.1225 & 0.3656 & 1.0000 & 1 \\
\hline $\mathbf{A}_{\mathbf{3}}$ & 0.0781 & 0.3155 & 0.6398 & 3 \\
\hline
\end{tabular}


Tablo 5: Kwong-Bai Yöntemine Göre Alternatiflerin Değerlendirilmesi

\begin{tabular}{|c|c|c|c|c|}
\hline Alternatifler & Toplam & Normal & Ideal & Siralama \\
\hline A1 & 0.0851 & 0.3063 & 0.6411 & 3 \\
\hline A2 & 0.1220 & 0.3713 & 1.00 & 1 \\
\hline A3 & 0.0756 & 0.3224 & 0.6413 & 2 \\
\hline
\end{tabular}

Bulanık sayıların sıralanması için kullanılan kareli ortalamalar ve Kwong-Bail yöntemi sonuçları birbirine yakın sonuçlar verse de kareli ortalamalar yönteminde birinci alternatif en iyi tercih iken bu alternatif diğer yöntemde son sıradadır. İki yönteme göre en iyi sonuç ikinci alternatif yani hibrit kuledir.

\section{Sonuç}

Temiz enerji kaynağı çeşidi olan rüzgar enerjisinin elde edilmesinde kullanılan rüzgar enerjisi santrallerinin maliyetini doğrudan etkileyen önemli bir yapı bileşeni türbin kuleleridir. $\mathrm{Bu}$ çalışmada çelik, betonarme ve hibrit (çelik+betonarme) türbin kuleleri dikkate alınmıştır. Ayrıca bu çalışmada, türbin santralinin yapısal dayanımı ve diğer bileşenlerin sağlıklı çalışabilmesi için kule uç yer değiştirmeleri ve kule taban gerilmeleri emniyetli sınırlar içerinde en güvenli oldukları durumlar dikkate alınarak en iyi alternatif hesaplanmıştır. Bulanık AHP yönteminin daha önce literatürde bu alanda kullanılmadığı görüldüğü için literatürde bir boşluk olduğu söylenebilir. Bu çalışma ile bu boşluk doldurulmuş ve literatüre katkı sunulmuştur. Yapılan çalışmanın sonucuna göre hibrit kulenin kriterleri en uygun düzeyde sağlayan alternatif olduğu görülmüştür. Gelecek çalışmalar açısından bu problem farklı çok kriterli karar verme yöntemleri kullanılarak da çözülebilir. PROMETHEE, TOPSIS veya VIKOR yöntemleri ile yeni çözümler elde edilebilir. Bunun dışında matematiksel modeller, doğrusal fiziki programlama veya lineer programlama ile problem genişletilerek yeni bulgular da elde edilebilir ve sonuçlar kıyaslanabilir.

\section{Kaynakça}

Abbate, G.B., (2013), Optimal Control for Fatigue Reduction of a Ballast-Stabilized Floating Wind Turbine. Department of Electronic Systems, Allborg University, Denmark, 2013.

Akpınar, M. E. (2016). Vikor tabanlı yeni bir çok kriterli sinıflandırma metodu: Vikorsort. (Yüksek Lisans Tezi). Pamukkale Üniversitesi Fen Bilimleri Enstitüsü, Türkiye.

Arslan T., ve Khirsty, J., (2006). A Rational Approach to Handling Fuzzy Perceptions in Route Choice. Europen Journal of Ope-rational Research, 168(29), 571-583.

Artun, O., (2020), Determination of the Suitable Areas for The Investment of the Wind Energy Plants (WEP) in Osmaniye Using Analytical Hierarchy Process (AHP) and Geographic Information Systems (GIS). Avrupa Bilim ve Teknoloji Dergisi, (20), 196-205.

Chang, D.Y., (1996), Applications of the extent analysis method on fuzzy AHP. European Journal of Operational Research. 95, 649-655.
Che, Z., Wang, H., ve Chuang, C.L., (2010), A Fuzzy AHP and DEA Approach for Making Bank Loan Decisions For Small and Medium Enterprises in Taiwan. Expert Systems with Applications, 37(10), 7189-7199.

Elibüyük, U. ve Üçgül, İ., (2014), Rüzgar Türbinleri, Çeşitleri ve Rüzgar Enerjisi Depolama Yöntemleri. Süleyman Demirel Üniversitesi, $\quad$ Yekarum e-Dergi, https://dergipark.org.tr/tr/download/article-file/204144

Gkantou, M., Baniotopoulos, C., ve Martinez-Vazquez P., (2017)., Tall Hybrid Wind Turbine Towers Load Analysis and Structural Response. The International Conference on wind Enerfy Harvesting-2017. 209, 87-90, Coimbra, Portugal, 20-21 April 2017.

Harte, R., Gideon P.A.G., ve Zijl, V., (2007), Structural Stability of Concrete Wind Turbines and Solar Towers Exposed to Dynamic Wind Action. Journal of Wind Engineering and Industrial Aerodynamics. 95, 1079-1096.

Kanbur, F.A., (2014), Steel Tower Design for a $500 \mathrm{KW}$ Wind Turbine. (The Degree of Master Thesis). İstanbul Technical University, Graduate Scholl of Natural, İstanbul, Turkey.

Kocer, F.Y. ve Arora, J.S., (1996), Design of Prestressed Concrete Transmission Poles: Optimization Approach. Journal of Structural Engineering, 122(7), 804-814.

Krishnendu, S., Ravi, S., Surendra, S.Y., ve Lakshman, S.T., (2012), Supplier Selection Using Fuzzy AHP and Fuzzy Multi-Objective Linear Programming for Developing low Carbon Supply Chain. Expert Systems with Applications. 39(9), 8182-8192.

Laxson, A., (2001), WindPACT Turbine Design Scaling Studies Technical Area 3-Self-Erecting Tower and Nacelle Feasibility. National Renewable Energy Laboratory (NREL). March 2001.

Lee, S.K., Kon, S., Mogi, G., Li, Z., Hui, K.S., Lee, S.K., . . . Kim, J.W., (2010), Econometric Analysis of the R\&D Performance in the National Hygrogen Energy Technology Development for Measuring Relative Efficiency: The fuzzy AHP/DEA Integrated Model Approach. International Journal of Hydrogen Energy. 35(6), 2236-2246.

Lewin, T.J., (2010), An Investigation of Design Alternatives for 328-ft (100-m) Tall Wind Turbine Towers. The Degree of Master Thesis, Iowa State University, Iowa, USA.

Lin, H.F., (2010), An Application of Fuzzy AHP for Evaluating Eour-seWebsite Quality. Computers \& Education. 54(4), 877-888.

Liu, Y., Eckert, C. M., ve Earl, C. (2020). A review of fuzzy AHP methods for decision-making with subjective judgements. Expert Systems with Applications, 161, 113738.

Lyu, H. M., Sun, W. J., Shen, S. L., ve Zhou, A. N. (2020). Risk assessment using a new consulting process in fuzzy AHP. Journal of Construction Engineering and Management. 146(3), 04019112.

Manwel, J.F., Mcgowan, J.G., ve Rogers, A.L., (2009), Wind Energy Explained Theory. Design and Application Second Edition. John Wiley \& Sons, Ltd.U.K. 
Moan, T., (2017), Recent developments of analysis and design of floating wind turbines. The International Conference on Wind Energy Harvesting-2017. 17-34, Coimbra Portugal, 20-21 April 2017.

Negm, H.M., ve Maalawi, K.Y., (1999), Structural Design Optimization of Wind Turbine Towers. Computers and Structures. 74, 649-666.

Orlando, D., (2011), Computer-aided Maintenance Management Sys-tems Selection Based on a Fuzzy AHP Approach. Advances in Engine-ering Software. 42(10), 821-829.

Paksoy, T., Pehlivan N.Y. ve Kahraman, C., (2012), Organizational Strategy Development in Distribution Channel Manage-ment using Fuzzy AHP and Hierarchical Fuzzy TOPSIS. Expert Sys-tems with Applications. 39(3), 2822-2841.

Price, T., (2004), Oxford Dictionary of National Biography (online ed.). Oxford University Press. doi: https://doi.org/10.1093/ref:odnb/100957

Quilligan, A., O’Connor, A., ve Pakrashi, V., (2012), Fragility Analysis of Steel and Concrete Wind Turbine Towers. Engineering Structures. 36, 270-282

Richter, C., Mohammadi, M.R.S., Pak, D., Rebelo, C., ve Feldmann, M., (2017), Showtime Stell Hybrid onshore Wind Towers Installed With Minimal Effort Development of Lifting Proces. The International Conference on wind Enerfy Harvesting-2017. 209, 87-90, Coimbra, Portugal, 20-21 April 2017.

Soğukpınar, H., Bozkurt, İ., Baran, M.F., Türkmenler, H., Pala, M., Engin, K.E., ve Kaya, A.İ., (2015), Micro-Turbine Design, Production and Testing. International Journal of Engineering Technologies. 1(4), 141-145 https://dergipark.org.tr/tr/download/article-file/253269

Şermet, F., Yiğit, M.E., ve Hökelekli, E., (2019), Dynamic Analysis of Different Type of Wind Turbine Towers Due to Wind and Earthquake Effect. International Civil Engineering \& Architecture Conference (ICEARC 2019). Trabzon, TURKEY, 17-20 April 2019.

Taha, Z., ve Rostam, S., (2011), A Hibrid Fuzzy AHPPROMETHEE Decision Support System for Machine Tool Selection in Flexible Manufacturing cell. Journal of Intelligent Manufacturing. 23(6), 2137-3149.

Uzoka, F.M.E., Obat, O., Barker K., ve Osuji, J., (2011), An Experimental Comparison of Fuzzy Logic and AHP for Medical Decision Support Systems. Computer Methods and Programs Biomedicine. 103(1), 10-27.

WindEurope, (2020), Wind energy in Europe in 2019, European Statistics Archive. [Online]. 13 Kasım 2020 tarihinde https://windeurope.org/aboutind/statistics/european/windenergy-in-europe-in-2019/ adresinden erişildi.

Yavuz, İ., ve Özbay, H., (2020), Rüzgar Türbinlerinde Kurulum ve Bakım Süreçleri: Bandırma Örneği. Mühendislik Bilimleri ve Araştırmalarl Dergisi. 2, 58 - 68.

Yiğit, M.E., Özdemir, A., Şermet, F., ve Pınarlık, M., (2018), Analysis of Offshore Wind Turbine Towers with Different Designs by Finite Elements Method. 9 th International
Conference on Engineering, Technology, Management and Science 2018 (ICETMS 2018). Barcelona, Spain, 1st \& 2nd July 2018. 